\title{
Clocinnamox inhibits the intravenous self-administration of opioid agonists in rhesus monkeys: comparison with effects on opioid agonist-mediated antinociception
}

Received: 10 May 1996 / Final version: 27 August 1996

\begin{abstract}
The effects of CCAM, an insurmountable mu opioid receptor antagonist, were studied on the intravenous self-administration and thermoantinociception of alfentanil and nalbuphine, high- and low-efficacy opioid agonists, respectively, in rhesus monkeys. A single dose of $0.1 \mathrm{mg} / \mathrm{kg}$ CCAM IV reduced alfentanil's reinforcing potency in an FR30 TO 45s schedule 10-fold within a 24-h period. The maximum response rates remained essentially unchanged. At $1 \mathrm{mg} / \mathrm{kg}$, CCAM caused a 300-fold shift of the alfentanil dose-response curve and also depressed the maximum response rates. CCAM also blocked insurmountably responding for nalbuphine, which was essentially abolished in two of three animals after a dose of $0.1 \mathrm{mg} / \mathrm{kg}$ CCAM and in all animals after $1 \mathrm{mg} / \mathrm{kg}$. The acute insurmountable antagonism of alfentanil and nalbuphine self-administration by CCAM was used to determine the (relative initial) efficacy values of both agonists. Efficacy values, tau, were 391 for alfentanil and 196 for nalbuphine; the apparent in vivo dissociation constants, $\mathrm{K}_{\mathrm{A}}$, were $0.16 \mathrm{mg} / \mathrm{kg}$ per injection (i.e., $350 \mathrm{nmol} / \mathrm{kg}$ per injection) for alfentanil and $0.14 \mathrm{mg} / \mathrm{kg}(370 \mathrm{nmol} / \mathrm{kg}$ per injection) for nalbuphine. In comparison, in a rhesus monkey $50^{\circ} \mathrm{C}$ warm-water tail withdrawal assay, the tau values were 11 for alfentanil and 0.92 for nalbuphine, and the $\mathrm{K}_{\mathrm{A}}$ values were $0.2 \mathrm{mg} / \mathrm{kg}(440 \mathrm{nmol} / \mathrm{kg})$ for alfentanil and $0.15 \mathrm{mg} / \mathrm{kg}$ (400 nmol/ $\mathrm{kg}$ ) for nalbuphine. Therefore, it seems that the higher potency of alfentanil and nalbuphine
\end{abstract}

G. Zernig $(\bowtie)^{1} \cdot$ J.H. Woods

Department of Pharmacology, University of Michigan,

1301 Medical Science Research Building III,

Ann Arbor, MI 48109-0632, USA

J.H. Woods

Department of Psychology, University of Michigan,

1301 Medical Science Research Building III,

Ann Arbor, MI 48109-0632, USA

J.W. Lewis

Department of Chemistry, University of Bristol, Bristol, UK

Present address:

${ }^{1}$ Universitätsklinik für Psychiatrie, Auenbruggerplatz 22,

A-8036 Graz, Austria

FAX (+43) 316/385-3556; e-mail: gerald.zernig@kfunigraz.ac.at in self-administration as compared to thermal antinociception in rhesus monkeys is predominantly due to a larger efficacy of the same agonist in self-administration (i.e., a larger receptor pool) rather than differences in apparent in vivo affinity.

Key words Apparent in vivo affinity - Alfentanil · Antinociception · Clocinnamox · Efficacy $\cdot$ Mu receptors · Nalbuphine · NIH 10443 - Operant responding ·

Opioid receptors - Receptor reserve - Reinforcement ·

Self-administration $\cdot$ Spare receptors

\section{Introduction}

In a variety of assays, clocinnamox (CCAM) acts as an insurmountable antagonist of mu opioid receptors (Comer et al. 1992; Burke et al. 1994; Zernig et al. 1994, 1995a,b; 1996a). Furthermore, CCAM, in contrast to the irreversible mu opioid antagonist beta-funaltrexamine (Portoghese et al. 1980; Takemori et al. 1981), is devoid of any opioid agonistic activity (Comer et al. 1992; Zernig et al. 1994) and has greater potency when injected systemically (Zernig et al. 1995a). This renders CCAM a useful tool to measure agonist efficacies and apparent in vivo affinities using the method of partial irreversible antagonism as pioneered by Furchgott (1966) and later refined by Black and Leff (1983).

Opioid agonists display a much higher potency in self-administration than in antinociception (Zernig et al. 1994; Walker et al. 1995). It is much more likely that this potency difference is due to a larger mu opioid receptor pool mediating the reinforcing properties of mu agonists (expressed as a larger efficacy) rather than different mu receptor subtypes mediating the respective behavior (expressed as different apparent in vivo affinities). To test this possibility, two prototypical mu opioid agonists were chosen, alfentanil (generally considered a high-efficacy agonist) and nalbuphine (considered a low-efficacy agonist; Walker et al. 1995), and were tested in each procedure with and without pretreatment with CCAM. 
In Furchgott's model, efficacy is a direct measure of the relative size of the receptor pool mediating the response under investigation. For example, an efficacy of 5 indicates that only one-fifth of all receptors are necessary to give a half-maximal effect under control conditions. The apparent in vivo affinity, or, more precisely, the apparent in vivo dissociation constant, $\mathrm{K}_{\mathrm{A}}$, gives the agonist's affinity for the receptor under investigation in a form that allows direct comparison with the agonist's affinity as determined by in vitro molecular pharmacological techniques. Thus, a $\mathrm{K}_{\mathrm{A}}$ of $0.16 \mathrm{mg} / \mathrm{kg}$ for alfentanil $\mathrm{HCl}$ (molecular weight, 453) would correspond to $350 \mathrm{nmol} / \mathrm{kg}$, or, assuming a specific body tissue weight of one, $350 \mathrm{nM}$, which can be directly compared to the drug's dissociation constant, $\mathrm{K}_{\mathrm{D}}$ or $\mathrm{K}_{\mathrm{i}}$, in radioligand binding assays. A direct comparison might, in the case of greatly different in vivo dissociation constant $\left(\mathrm{K}_{\mathrm{A}}\right)$ and $\mathrm{K}_{\mathrm{i}}$ values, reveal considerable compartmentalization and/or rapid elimination, as was shown previously in mice (Zernig et al. 1995b). In self-administration, the actual operant schedule used has been shown to influence agonist potency (Young et al. 1981; Winger et al. 1992). In this case, determination of the agonists' apparent in vivo affinity and efficacy could test the prediction that the observed differences are due to differences in efficacies and not due to differences in affinity, as has been shown for antagonists by $\mathrm{pA}_{2}$ analysis (Bertalmio and Woods 1989).

\section{Materials and methods}

\section{Animals}

The effects of CCAM on the self-administration of both opioid agonists were determined in seven rhesus monkeys (Macaca mulatta), four males (\#CUR, \#HEN, \#ROS, \#SOC) and three females (\#HIL, \#JAN, \#UNA). The weight of the animals ranged from 4.8 to $11.7 \mathrm{~kg}$. The animals were individually housed in $83 \times 76 \times 91 \mathrm{~cm}$ deep stainless steel cages under a 12-h light cycle (lights on at 0700 hours) and tested in their home cages. They were fed twice daily, approximately 20 chows per monkey per feeding, at least 30 min before the start of each session, and were given ad libitum access to water. For the antinociception experiments, four different female monkeys (\#ALE, \#BUT, \#MEL, \#MER; weight, 7.0-9.4 kg) were used.

\section{Self-administration apparatus}

As detailed by Winger et al. (1989), the monkeys had intravenous silicone rubber catheters (inner diameter, $1 \mathrm{~mm}$; Mox-Med, Portage, Wisc., USA) implanted during aseptic surgery. The catheter was inserted through a jugular, femoral, or brachial vein and its tip positioned in the vicinity of the right atrium. Each animal wore a stainless-steel tubular harness connected to a flexible spring arm (Deneau et al. 1969) which was in turn connected to the back of the cage. The catheter exited the body at a mid-scapular site, where it was protected from the animal's fingers by the tubular harness and a Teflon web jacket (Alice King Chatam Medical Arts, Los Angeles, Calif., USA). The catheter passed through the flexible arm, exited the cage at the rear and was connected to infusion sets. Drugs or saline were dissolved in physiological saline and delivered by roller infusion pumps (Watson and Marlow Co., model MHRK 55, Falmouth, UK).
On the side of each monkey's cage was a light-lever panel, measuring $15.4 \mathrm{~cm}^{2}$. The panel contained two response levers (model 121-07, BRS-LVE, Beltsville, Md., USA), and over each lever a stimulus light that could be illuminated red. The rightmost red light was the discriminative stimulus, signaling drug availability. Between the two red stimulus lights was a similar light that could be illuminated green. This center light was lit during all infusions (saline or drug) for the duration of the pump action.

\section{Self-administration procedure}

Each experimental session lasted $130 \mathrm{~min}$ and was divided into four components lasting either $25 \mathrm{~min}$ or until 20 injections had been taken. The dose of drug delivered was different in each component; thus, a total of four different drug doses could be self-administered by the animal in one session. The components were separated from each other by a 10-min time out during which all lights were extinguished and responses had no consequences. Two sessions were scheduled each day, one starting at approximately 1000 hours and the other starting at approximately 1600 hours. Illumination of the red stimulus light signaled the availability of drug infusions during each component. Drug was delivered contingently on responding on the rightmost lever on a fixed ratio 30 response time out $45 \mathrm{~s}$ (FR30 TO $45 \mathrm{~s}$ ) schedule. Thirty responses resulted in drug infusion. Each infusion was followed by a 45-s period in which all lights were extinguished, and responding had no programmed consequences. Doses per injection were varied across components by varying the duration of the injections $(0.1$, $1.7,5.0$, and $16.7 \mathrm{~s}$ pump duration). Under control conditions, the unit doses (i.e., $\mathrm{mg} / \mathrm{kg}$ per injection) offered to the animal for selfadministration ranged from 0.00003 to 0.003 for alfentanil and 0.0003 to 0.03 for nalbuphine (i.e., the animals had different sensitivities). For alfentanil, four different orders of unit dose presentation (order 1: $0.5,1.7,5$, and $16.7 \mathrm{~s}$ pump duration; order 2: 1.7, $16.7,0.5$, and $5 \mathrm{~s}$; order $3: 5,0.5,16.7$, and $1.7 \mathrm{~s}$; and order 4 : $16.7,5,1.7$, and $0.5 \mathrm{~s}$ pump duration) were used in a random fashion; for nalbuphine, doses were presented in an ascending order. Three of the six monkeys (\#CUR, \#HEN, \#JAN) had histories of stable alfentanil- (\#CUR, \#JAN) or cocaine- (\#HEN) self-administration for several months. Three monkeys (\#HIL, \#ROS, \#SOC) were drug-naive and had to be trained to respond for alfentanil (starting dose, $0.0003 \mathrm{mg} / \mathrm{kg}$ ) on a FR $\times \mathrm{TO} 45 \mathrm{~s}$ schedule using the following response requirements in increasing order: $1,2,4,6,8$ etc. to $20,25,30$ (or 20, 22, 26, 30; \#ROS). These three monkeys acquired stable operant responding for alfentanil within 10-12 days (\#HIL, \#SOC) or 22 days (\#ROS). Following administration of CCAM, the dose range for nalbuphine and alfentanil was usually increased to follow the decreased potency of these compounds. Under these circumstances, the unit doses were presented in ascending order. On one occasion in two monkeys (\#CUR, \#HIL), the control dose range for alfentanil was maintained following administration of $1 \mathrm{mg} / \mathrm{kg}$ CCAM to demonstrate the loss of effectiveness of these doses and to record the recovering sensitivity to alfentanil. Saline was substituted frequently. Rates of saline-contingent responding were required to be $\leq 0.5$ responses per second at each infusion duration. If rates were higher, saline was retained as the response contingent consequence until rates reached this criterion level.

To determine control dose-response ranges, opioid agonist dose-response curves were determined until responding became stable, i.e., until changes in maximum response rate maintained by the drug were $<50 \%$ of the value for the maximum response rate of the previous drug session, and until the dose unit that maintained maximum response rates differed $\leq 0.5 \mathrm{log}$ from the previous drug session. Most animals were tested with more than one opioid agonist in pseudo-random order. CCAM was administered in a single dose of 0.1 or $1 \mathrm{mg} / \mathrm{kg}$ intravenously at approximately 1600 hours or 2000 hours and responding for opioid agonists or saline was tested from the next morning session on. Whenever CCAM was administered at 1600 hours, care was taken that only saline had been offered in the session preceding the CCAM ad- 
ministration. Thus, the first determination of drug-reinforced responding was started approximately $0.6-0.8$ days, the second one approximately $0.8-1$ days after CCAM treatment (maximal variation, $1 \mathrm{~h}$ ). In some experiments, a first dose of $1 \mathrm{mg} / \mathrm{kg}$ CCAM was followed by repeated daily administration of $0.1 \mathrm{mg} / \mathrm{kg}$ CCAM.

Warm-water tail withdrawal procedure

The thermoantinociceptive effects of nalbuphine were determined as described in detail previously (Dykstra and Woods 1986; Zernig et al. 1994). Briefly, the monkeys were seated in restraint chairs and the lower half of their shaved tails was dipped in an insulating container filled with water maintained at 40,50 , or $55^{\circ} \mathrm{C}$. After adaptation, the monkeys typically kept their tails in the $40^{\circ} \mathrm{C}$ water for at least $20 \mathrm{~s}$. Cutoff latency for all temperatures was set at $20 \mathrm{~s}$. A cumulative dosing procedure (15 min injection-test interval, 30 min inter-injection interval) was used to determine the effects of nalbuphine on tail withdrawal latencies the increase of which was taken as a measure of nalbuphine's antinociceptive effect. All experimental protocols were approved by the University of Michigan's University Committee on the Use and Care of Animals (UCUCA).

\section{Data analysis}

For the self-administration experiments, the dependent behavioral measure, i.e., responses per second at a certain unit dose, was averaged for each component of the session. In order to obtain representative control dose-response curves for each drug, data from individual sessions were averaged and are expressed as means \pm SEM of $n$ experimental sessions unless indicated otherwise. Dose-response curves after CCAM administration were excluded from this control curve pool until they had returned to pre-CCAM levels. A dose-response relationship was considered as having returned to control levels if (1) the maximum response rate occurred at the preCCAM unit dose and if (2) the maximum rate was not more than one standard error below the average pre-CCAM control. Usually, three such dose-response curves had to be obtained before the subsequent curves were used for the control pool again. The ascending parts of the control dose-response relationships were used to fit logistic dose-response curves to the data points using the commercially available package InPlot (GraphPad, San Diego, Calif., USA) to obtain values for $\mathrm{ED}_{50 \text {,control }}$ and the maximum observed agonist effect, $\mathrm{E}_{\mathrm{Am}}$. For the warm-water tail withdrawal experiments, the dependent behavioral measure, i.e., the tail withdrawal latency, was averaged across all four tested monkeys for each nalbuphine dose and also fitted to logistic dose-response curves.

Agonist efficacy, tau (or, more precisely, the tau value of the agonist dose-response relationship under control condition, tau $_{\text {con- }}$ trol); apparent in vivo affinity, $\mathrm{K}_{\mathrm{A}}$; the theoretically attainable maximum effect, $\mathrm{E}_{\mathrm{m}}$; a "signal transduction" factor, $\mathrm{n}$; and the fraction of receptors available after partial insurmountable antagonism with CCAM, q; were determined using the model by Black and Leff (1983) extended by q as defined by Furchgott (1966) according to the following equation:

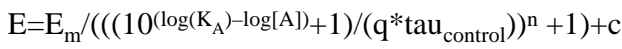

where $\mathrm{E}$ is the effect, [A] the agonist concentration, and $\mathrm{c}$ the baseline effect (i.e., operant level in the case of the self-administration experiments and baseline tail withdrawal latency in absence of any agonist in the case of the warm-water tail withdrawal experiments). The actual procedure and the mathematical models and calculations involved have been described and discussed in great detail (Zernig et al. 1996b); the reader is referred to this methodological publication for any further details. In order to test the internal consistency of the analytical approach, the estimates of the Black and Leff parameters were taken to back-calculate the $\mathrm{ED}_{50}$ for the control dose-response curves as well as $\mathrm{E}_{\mathrm{Am}}$ also as detailed previously (Zernig et al. 1996b), using equations 9 and 10 of Black et al. (1985), respectively. Close agreement between ob- served and back-calculated values indicates internal consistency of the analytical procedure; wrong estimates for efficacy, apparent in vivo affinity or $\mathrm{n}$ slopes would result in discrepancies between back-calculated and observed values.

\section{Drugs}

Alfentanil $\mathrm{HCl}$ (molecular weight, 453) was provided by the National Institute on Drug Abuse (Washington, D.C., USA) and nalbuphine $\mathrm{HCl}$ (molecular weight, 377) was obtained from DuPont Pharmaceuticals (Wilmington, Del., USA). Clocinnamox (CCAM; 14ß-(p-chlorocinnamoylamino)-7,8-dihydro- $N$-cyclopro-

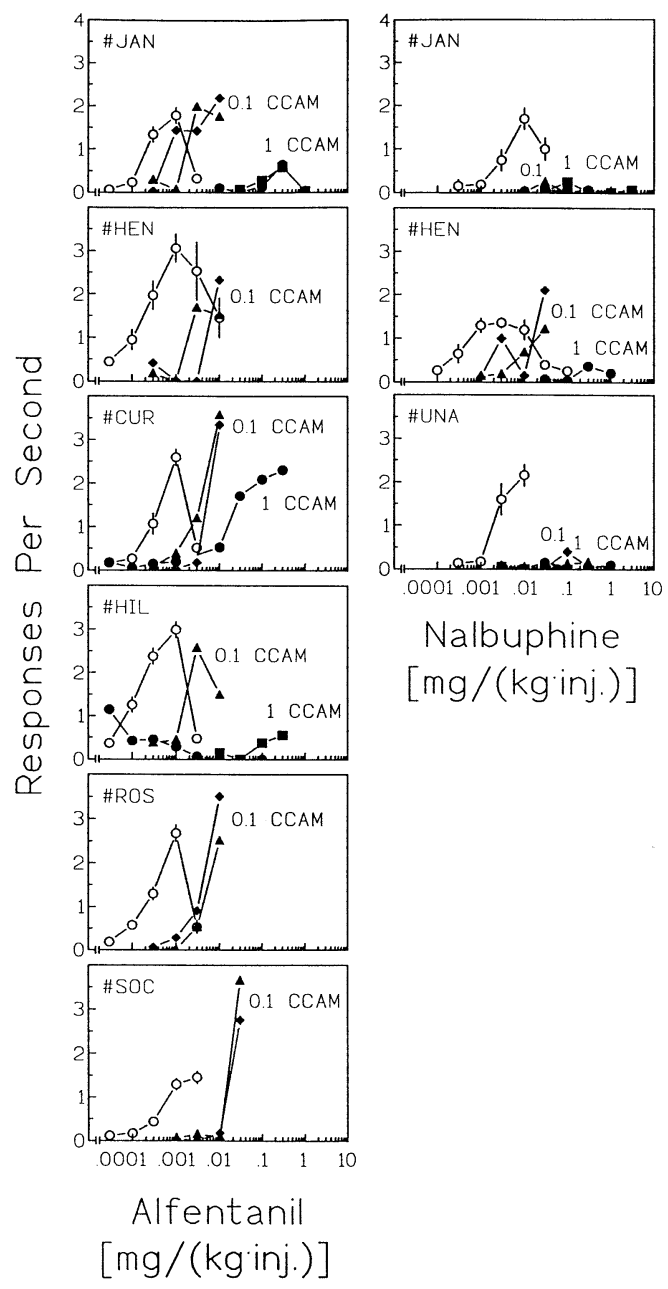

Fig. 1 The effects of clocinnamox on rates of responding maintained by the opioid agonists alfentanil (left column) and nalbuphine (right column) in rhesus monkeys. Shown are response rates maintained by the unit dose indicated on the $\mathrm{x}$-axis in $\mathrm{mg} / \mathrm{kg}$ per injection for each individual animal. Open circles, mean control response rates \pm SEM of 6-51 individual determinations per monkey. Filled symbols represent response rates determined in the first and/or second session, respectively, after a single dose of either $0.1 \mathrm{mg} / \mathrm{kg}$ (filled triangles, filled diamonds) or $1 \mathrm{mg} / \mathrm{kg}$ (filled circles, filled squares) CCAM. The first (morning) session was started 0.6-0.8 days after CCAM (given on the previous evening), the second (afternoon) session 0.8-1 day after the CCAM administration. In two monkeys (\#CUR, \#HIL), a high dose range and a low dose range were tested after $1 \mathrm{mg} / \mathrm{kg}$ CCAM on two different occasions. The identity of the monkey is given on the top left corner of the respective panel 


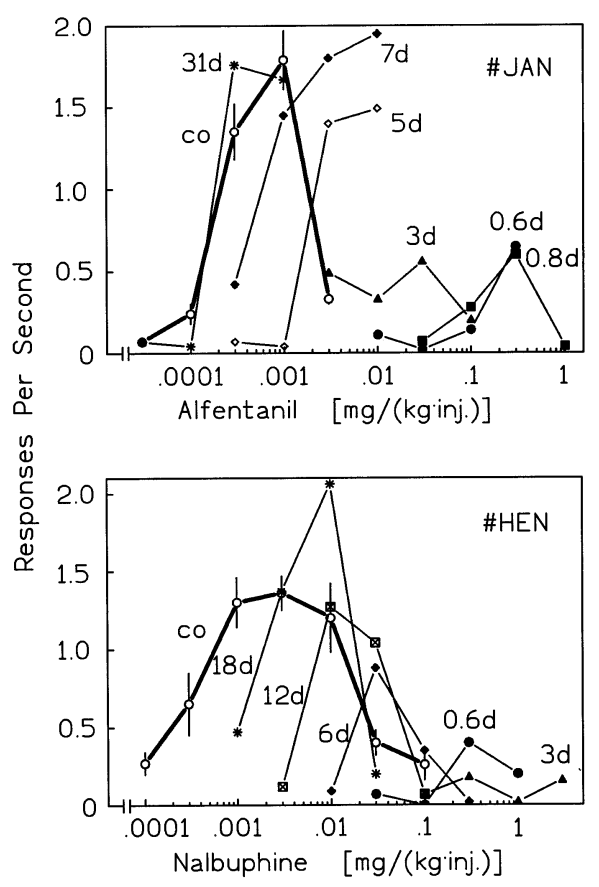

Fig. 2 Time course of recovery of response rates maintained by alfentanil and nalbuphine after clocinnamox administration. Shown are response rates maintained by the unit dose indicated on the $\mathrm{x}$-axis in $\mathrm{mg} / \mathrm{kg}$ per injection. CCAM was administered at an initial dose of $1 \mathrm{mg} / \mathrm{kg}$, followed by repeated administrations of $0.1 \mathrm{mg} / \mathrm{kg}$ every $24 \mathrm{~h}$. Top panel, alfentanil-maintained responding of monkey \#JAN. Open circles, mean control response rates control \pm SEM of 26 determinations. Dose-response curves for alfentanil were obtained 0.6 days (filled circles) and 0.8 days (filled squares) after the first CCAM dose (i.e., $1 \mathrm{mg} / \mathrm{kg}$ ), and 3 days (filled triangles), 5 days (open diamonds), 7 days (filled diamonds), and 31 days (asterisks) after the start of the experiment. The animal received its last $0.1 \mathrm{mg} / \mathrm{kg}$ CCAM dose on day 16 . Bottom panel, nalbuphine-maintained responding in monkey \#HEN. Open circles, mean control response rates control \pm SEM of 33 determinations. Dose-response curves for nalbuphine were obtained 0.6 days (filled circles) after the first CCAM dose (i.e. $1 \mathrm{mg} / \mathrm{kg}$ ), and 3 days (filled triangles), 6 days (filled diamonds), 12 days (boxed-in crosses), and 18 days (asterisks) after the start of the experiment. The animal received its last $0.1 \mathrm{mg} / \mathrm{kg}$ CCAM dose on day 20

pylmethylnor-morphinone mesylate) was synthesized by Dr. John Lewis and coworkers (University of Bristol, Bristol, UK) and dissolved in $1 \%(\mathrm{v} / \mathrm{v})$ lactic acid in sterile water at a concentration of $1 \mathrm{mg} / \mathrm{ml}$. Drug stock solutions in sterile water were diluted in sterile physiological saline.

\section{Results}

CCAM effects on intravenous self-administration of opioid agonists in rhesus monkeys

In the absence of CCAM, drug self-administration maintained the following maximum rates of responding (responses/s; mean and range): alfentanil, 2.3 (1.5-3.0); and nalbuphine, 1.7 (1.4-2.2). Furthermore, responding maintained by intravenous injections of nalbuphine occurred at an average maximum response rate of $>1.2$ responses $/ \mathrm{s}$ in only three of seven tested monkeys; data from the other four monkeys tested with nalbuphine are therefore not included in the present study. A 14- to 24-h pretreatment with CCAM modified self-administration of alfentanil in the following way: A dose of $0.1 \mathrm{mg} / \mathrm{kg}$ CCAM shifted the alfentanil dose-response curves to the right while maximum response rates remained essentially unchanged. Following administration of $1 \mathrm{mg} / \mathrm{kg}$, CCAM caused a further rightward shift of the alfentanil dose-response curve and also markedly depressed the maximum response rates in two of three animals tested (Fig. 1).

CCAM at a dose of $0.1 \mathrm{mg} / \mathrm{kg}$ shifted $\mathrm{E}_{\mathrm{Am}}$, i.e., the unit dose (i.e., $\mathrm{mg} / \mathrm{kg}$ per injection) at which alfentanilmaintained responding was maximal on average 10-fold, from 0.001 to $0.01 \mathrm{mg} / \mathrm{kg}$ per injection. In four of six tested monkeys, the maximum response rate was slightly increased, in two of the six monkeys it was slightly decreased compared to control responding. Thus, $0.1 \mathrm{mg} / \mathrm{kg}$ per injection CCAM did not change the average maximum response rates. Pretreatment with $1 \mathrm{mg} / \mathrm{kg}$ CCAM, however, depressed maximum alfentanil-maintained response rates in two of three monkeys tested while at the same time shifting $\mathrm{E}_{\mathrm{Am}}$ in all three monkeys 300 -fold, from $0.001 \mathrm{mg} / \mathrm{kg}$ per injection to $0.3 \mathrm{mg} / \mathrm{kg}$ per injection. However, even after $1 \mathrm{mg} / \mathrm{kg}$ CCAM, maximum response rates were above 0.5 responses/s in all three animals tested.

The effects of CCAM pretreatment on nalbuphinemaintained responding are shown in the right column of Fig. 1. Under control conditions, maximum response rates were obtained at unit doses ranging from 0.001 to $0.01 \mathrm{mg} / \mathrm{kg}$ per injection; nalbuphine maintained maximum rates of responding of $>1.2$ per second in only three of seven monkeys. $0.1 \mathrm{mg} / \mathrm{kg}$ CCAM pretreatment produced a 10-fold parallel shift of the dose-response curve in one monkey (\#HEN), whereas it markedly decreased responding in two other animals (\#UNA, \#JAN). At $1 \mathrm{mg} / \mathrm{kg}$, CCAM flattened the nalbuphine dose-response curve in all three animals (maximum response rates $<0.5$ responses/s). One of these two animals (\#JAN) had shown only parallel shifts for alfentanil-maintained responding by $0.1 \mathrm{mg} / \mathrm{kg}$ CCAM on previous occasions. After completion of the nalbuphine trials, this animal was challenged again with $0.1 \mathrm{mg} / \mathrm{kg}$ CCAM and tested for alfentanilmaintained responding; again, the alfentanil dose-response curve was shifted in a parallel fashion (data not shown).

On day 1 after CCAM administration, there was no significant recovery of the animal's sensitivity to alfentanil or nalbuphine, as evidenced by the overall identical dose-response curve shifts on the first (i.e., morning) and second (i.e., afternoon) session after CCAM administration on the previous evening (Fig. 1). At later times, however, opioid agonist sensitivity returned to pre-CCAM levels, i.e., maximum response rates increased again and dose-response curves shifted leftward to the pre-CCAM dose range (Fig. 2). The acute suppression of the mu opioid receptor population by CCAM (as evidenced by the decrease in $q$ values) was dose-dependent regardless of the agonist used to determine it: calculated from the alfentanil data, 


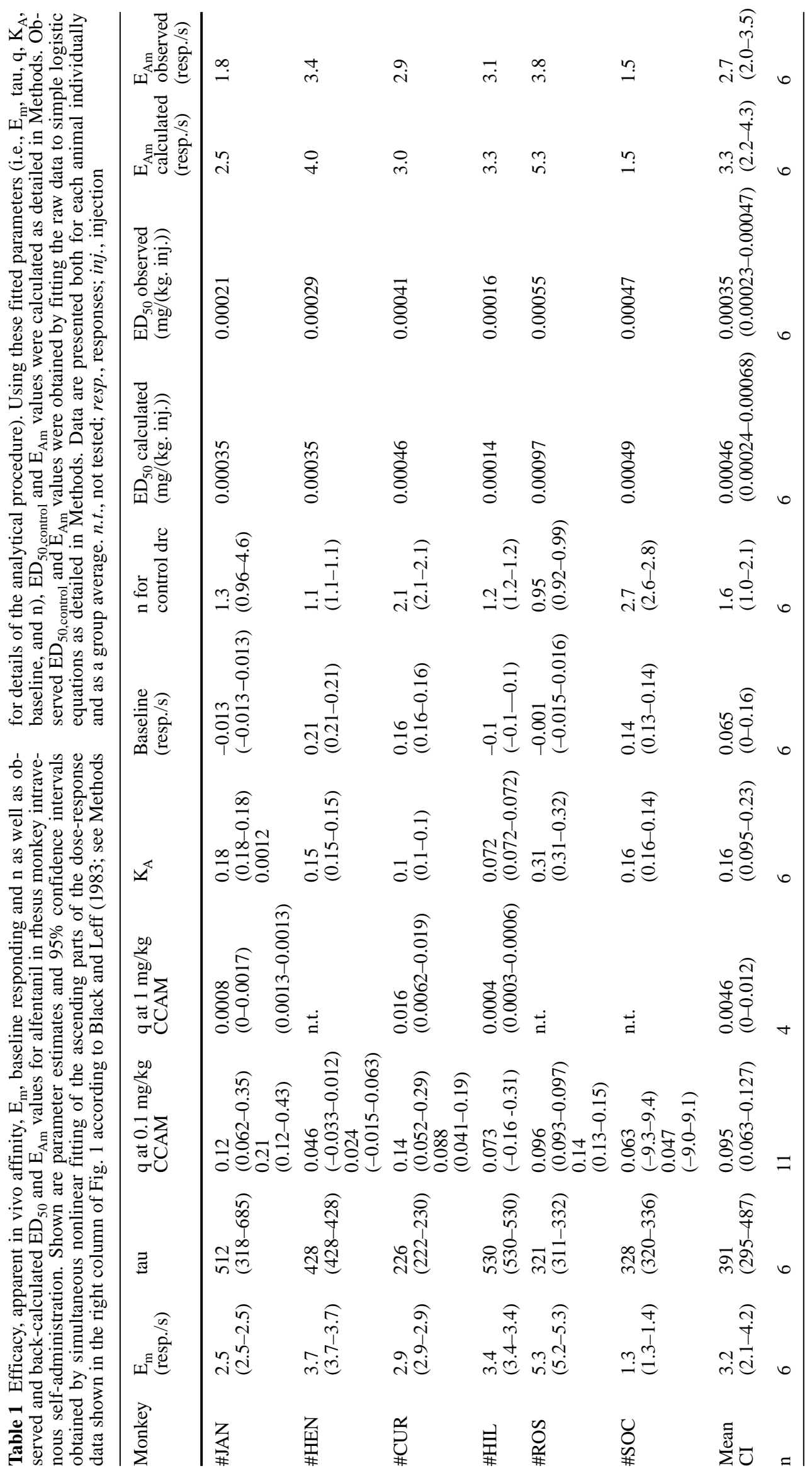




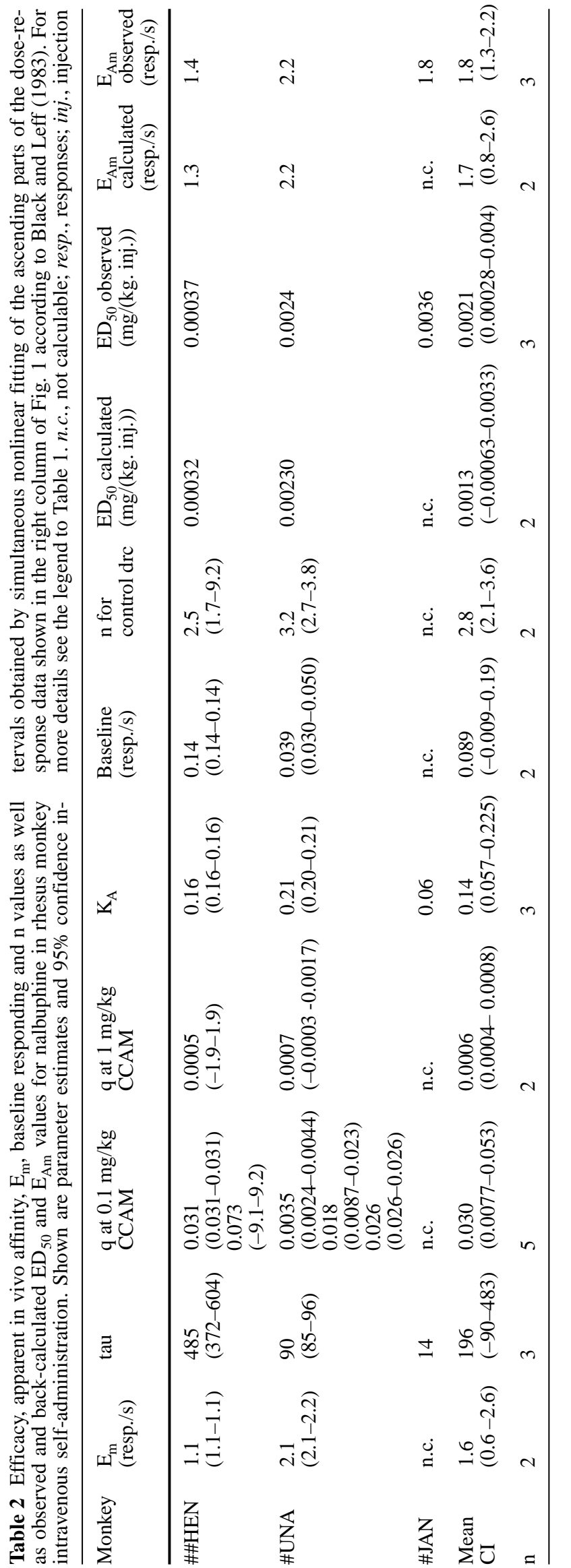

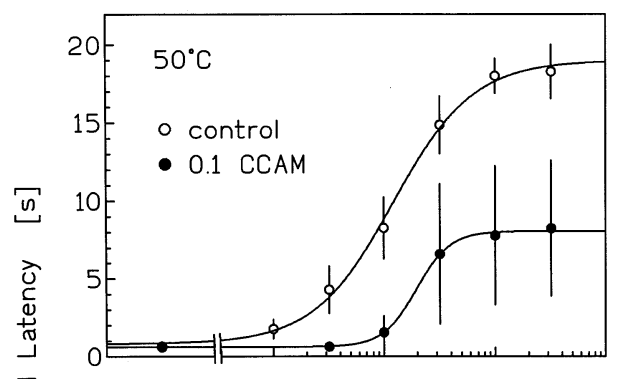

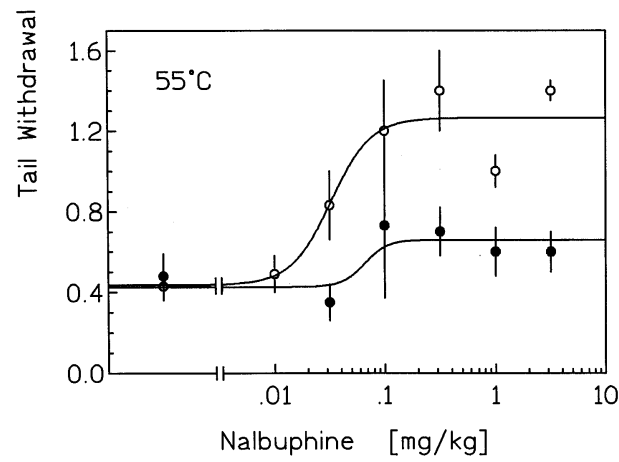

Fig. 3 The effects of clocinnamox on nalbuphine-mediated antinociception in a rhesus monkey warm-water tail withdrawal assay. Shown are mean tail withdrawal latencies \pm SEM of four monkeys obtained either before (open circles) or $12 \mathrm{~h}$ after administration of $0.1 \mathrm{mg} / \mathrm{kg}$ CCAM (CCAM) injected SC (filled circles). Tail withdrawal latencies at $50^{\circ} \mathrm{C}$ (top panel) and $55^{\circ} \mathrm{C}$ (bottom panel) were obtained within the same experiment. Control and nalbuphine control experiments were performed 7 days prior to the post-CCAM nalbuphine experiments. Note that the maxima of the $\mathrm{y}$-axis differ across panels

$0.1 \mathrm{mg} / \mathrm{kg}$ CCAM decreased the number of receptors to $9.5 \%$ of their pre-CCAM level, and $1 \mathrm{mg} / \mathrm{kg}$ CCAM suppressed them to $0.5 \%$ of their pre-CCAM level (Table 1). The respective values when determined with nalbuphine as the agonist were $3 \%$ at $0.1 \mathrm{mg} / \mathrm{kg} \mathrm{CCAM}$ and $0.1 \%$ at $1 \mathrm{mg} / \mathrm{kg}$ CCAM (Table 2). However, a comparison of the time periods necessary for complete recovery across different CCAM doses and agonists showed that, overall, no statistically significant CCAM dose-dependence could be found, although recovery time tended to be slightly shorter for alfentanil after a dose of $0.1 \mathrm{mg} / \mathrm{kg}$ CCAM than after $1 \mathrm{mg} / \mathrm{kg}$ CCAM. Thus, on average, alfentanil sensitivity recovered to pre-CCAM levels within 3.2 days $95 \%$ confidence interval (CI), 1.9-4.4 days; all six alfentanil animals tested after $0.1 \mathrm{mg} / \mathrm{kg}$ CCAM and within 4.7 days (CI, 0.9-8.5 days; three determinations in two monkeys) after $1 \mathrm{mg} / \mathrm{kg}$ CCAM (not shown). Nalbuphine sensitivity recovered within an average of 6 days (0-13 days; four determinations in three monkeys) after $0.1 \mathrm{mg} / \mathrm{kg}$ CCAM and within 4.3 days (2.9 -5.8 days; three determinations in two monkeys) after $1 \mathrm{mg} / \mathrm{kg}$ CCAM (not shown). Furthermore, the speed of recovery was not affected if the acute dose of $1 \mathrm{mg} / \mathrm{kg}$ CCAM was followed by administrations of $0.1 \mathrm{mg} / \mathrm{kg}$ CCAM every $24 \mathrm{~h}$; in all six experiments, sensitivity to alfentanil (Fig. 2, top panel) or nalbuphine (Fig. 2, bottom panel) returned to pre-CCAM levels despite the fact that $0.1 \mathrm{mg} / \mathrm{kg}$ CCAM was still given daily. 
Table 3 Efficacy, apparent in vivo affinity, $\mathrm{E}_{\mathrm{m}}$, baseline responding and $\mathrm{n}$ value as well as observed and back-calculated $\mathrm{ED}_{50 \text { control }}$ and $\mathrm{E}_{\mathrm{Am}}$ values for alfentanil and nalbuphine in rhesus monkey thermal antinociception. Shown are parameter estimates and $95 \%$ confidence intervals obtained by simultaneous nonlinear fitting of rhesus monkey warm-water tail withdrawal experiments according to Black and Leff (1983; see Methods for details of the analytical procedure). Data for alfentanil were obtained by reanalyzing previously published data (see Fig. 2 of Zernig et al. 1994) that had been analyzed according to Furchgott (1966). Parameter estimates for nalbuphine were obtained from the data shown in Fig. 3. Note that observed $\mathrm{ED}_{50, \text { control }}$ and $\mathrm{E}_{\mathrm{Am}}$ (i.e., maximum agonist effect) values were obtained by fitting the data to the general logistic dose-response function (see, e.g., Black et al. 1985). Therefore, the fitted $\mathrm{E}_{\mathrm{Am}}$ is larger than the experimental cutoff (i.e., $20 \mathrm{~s}$; see Methods for details). calc, calculated; obs, observed; $d r c$, dose-response curve

\begin{tabular}{|c|c|c|c|c|c|c|c|c|c|c|}
\hline $\begin{array}{l}\text { Compound } \\
\text { stimulus } \\
\text { intensity }\end{array}$ & $\begin{array}{l}E_{m} \\
(s)\end{array}$ & tau & $\begin{array}{l}\mathrm{q} \text { at } \\
0.1 \mathrm{mg} / \mathrm{kg} \\
\text { CCAM }\end{array}$ & $\mathrm{K}_{\mathrm{A}}$ & $\begin{array}{l}\text { Baseline } \\
\text { (s) }\end{array}$ & $\begin{array}{l}\mathrm{n} \text { for } \\
\text { control drc }\end{array}$ & $\begin{array}{l}\mathrm{ED}_{50} \\
\text { calc } \\
(\mathrm{mg} / \mathrm{kg})\end{array}$ & $\begin{array}{l}\mathrm{ED}_{50} \\
\text { obs } \\
(\mathrm{mg} / \mathrm{kg})\end{array}$ & $\begin{array}{l}\mathrm{E}_{\mathrm{Am}} \\
\text { calc } \\
\text { (s) }\end{array}$ & $\begin{array}{l}\mathrm{E}_{\mathrm{Am}} \\
\text { obs } \\
\text { (s) }\end{array}$ \\
\hline \multicolumn{11}{|l|}{ Alfentanil } \\
\hline $50^{\circ} \mathrm{C}$ & $\begin{array}{l}21 \\
(21-21)\end{array}$ & $\begin{array}{l}11 \\
(10-13)\end{array}$ & $\begin{array}{l}0.16 \\
(0.13-0.18)\end{array}$ & $\begin{array}{l}0.20 \\
(0.20-0.21)\end{array}$ & $\begin{array}{l}1.4 \\
(1.2-1.5)\end{array}$ & $\begin{array}{l}0.95 \\
(0.82-1.1)\end{array}$ & 0.016 & 0.021 & 22 & 21 \\
\hline $55^{\circ} \mathrm{C}$ & $\begin{array}{l}24 \\
(24-24)\end{array}$ & $\begin{array}{l}13 \\
(12-14)\end{array}$ & $\begin{array}{l}0.040 \\
(0.037-0.043)\end{array}$ & $\begin{array}{l}1.5 \\
(1.4-1.5)\end{array}$ & $\begin{array}{l}0.87 \\
(0.82-0.91)\end{array}$ & $\begin{array}{l}1.8 \\
(1.6-1.9)\end{array}$ & 0.12 & 0.10 & 24 & 21 \\
\hline \multicolumn{11}{|l|}{ Nalbuphine } \\
\hline $50^{\circ} \mathrm{C}$ & $\begin{array}{l}40 \\
(39-40)\end{array}$ & $\begin{array}{l}0.92 \\
(0.89-0.95)\end{array}$ & $\begin{array}{l}0.57 \\
(0.53-0.60)\end{array}$ & $\begin{array}{l}0.15 \\
(0.14-0.16)\end{array}$ & $\begin{array}{l}0.66 \\
(0.44-0.87)\end{array}$ & $\begin{array}{l}1.3 \\
(1.3-1.4)\end{array}$ & 0.12 & 0.12 & 19 & 19 \\
\hline $55^{\circ} \mathrm{C}$ & $\begin{array}{l}31 \\
(28-35)\end{array}$ & $\begin{array}{l}0.26 \\
(0.25-0.27)\end{array}$ & $\begin{array}{l}0.97 \\
(0.83-1.1)\end{array}$ & $\begin{array}{l}0.011 \\
(0.0067-0.017)\end{array}$ & $\begin{array}{l}0.42 \\
(0.37-0.47)\end{array}$ & $\begin{array}{l}2.6 \\
(2.5-2.7)\end{array}$ & 0.032 & 0.033 & 1.3 & 1.4 \\
\hline
\end{tabular}

Table 4 Comparison of efficacy and affinity values for alfentanil and nalbuphine in intravenous self-administration and thermal antinociception in rhesus monkeys

\begin{tabular}{|c|c|c|c|c|c|c|c|c|}
\hline & \multicolumn{4}{|c|}{ Alfentanil } & \multicolumn{4}{|c|}{ Nalbuphine } \\
\hline & tau & $\mathrm{K}_{\mathrm{A}}$ & $\begin{array}{l}\mathrm{ED}_{50} \\
\text { calculated }\end{array}$ & $\begin{array}{l}\mathrm{ED}_{50} \\
\text { observed }\end{array}$ & tau & $\mathrm{K}_{\mathrm{A}}$ & $\begin{array}{l}\mathrm{ED}_{50} \\
\text { calculated }\end{array}$ & $\begin{array}{l}\mathrm{ED}_{50} \\
\text { observec }\end{array}$ \\
\hline \multicolumn{9}{|c|}{ Self-administration } \\
\hline Mean & 391 & $\begin{array}{l}0.16 \\
(\mathrm{mg} / \mathrm{kg} \text { pe } \\
350 \\
\text { (nmol/kg } \\
\text { per inj.) }\end{array}$ & $\begin{array}{r}0.00046 \\
\text { injection) }\end{array}$ & 0.00035 & 196 & $\begin{array}{l}0.14 \\
(\mathrm{mg} / \mathrm{kg} \text { pe } \\
370 \\
\text { (nmol/kg } \\
\text { per inj.) }\end{array}$ & jection) & 0.0021 \\
\hline \multicolumn{9}{|c|}{ Thermoantinociception } \\
\hline $50^{\circ} \mathrm{C}$ & 11 & $\begin{array}{l}0.20 \\
(\mathrm{mg} / \mathrm{kg}) \\
440 \\
(\mathrm{nmol} / \mathrm{kg})\end{array}$ & $\begin{array}{l}0.016 \\
(\mathrm{mg} / \mathrm{kg})\end{array}$ & $\begin{array}{l}0.021 \\
(\mathrm{mg} / \mathrm{kg})\end{array}$ & 0.92 & $\begin{array}{l}0.15 \\
(\mathrm{mg} / \mathrm{kg}) \\
400 \\
(\mathrm{nmol} / \mathrm{kg})\end{array}$ & $\begin{array}{l}0.12 \\
(\mathrm{mg} / \mathrm{kg})\end{array}$ & $\begin{array}{l}0.12 \\
(\mathrm{mg} / \mathrm{kg})\end{array}$ \\
\hline $55^{\circ} \mathrm{C}$ & 13 & $\begin{array}{l}1.50 \\
(\mathrm{mg} / \mathrm{kg}) \\
3300 \\
(\mathrm{nmol} / \mathrm{kg})\end{array}$ & $\begin{array}{l}0.120 \\
(\mathrm{mg} / \mathrm{kg})\end{array}$ & $\begin{array}{l}0.100 \\
(\mathrm{mg} / \mathrm{kg})\end{array}$ & 0.26 & $\begin{array}{l}0.011 \\
(\mathrm{mg} / \mathrm{kg}) \\
29 \\
(\mathrm{nmol} / \mathrm{kg})\end{array}$ & $\begin{array}{l}0.032 \\
(\mathrm{mg} / \mathrm{kg})\end{array}$ & $\begin{array}{l}0.033 \\
(\mathrm{mg} / \mathrm{kg})\end{array}$ \\
\hline
\end{tabular}

The respective values were $5.5 \mathrm{~d}$ (2.4-8.6 days; $n=6)$ for alfentanil, and 6 days $(n=1)$ for nalbuphine.

The results of the analysis of the ascending parts of the unit dose-response rate relationships are summarized in Table 1 for alfentanil and in Table 2 for nalbuphine. The average efficacy of alfentanil in self-administration was found to be 391, that of nalbuphine to be 196. It should be noted, however, that the variance estimates were much larger for nalbuphine than for alfentanil. In contrast to the roughly 2-fold difference in efficacy, apparent in vivo affinities were almost identical $\left(\mathrm{K}_{\mathrm{A}}\right.$ for alfentanil, $0.16 \mathrm{mg} / \mathrm{kg}$ or $350 \mathrm{nmol} / \mathrm{kg}$ per injection, Table $1 ; \mathrm{K}_{\mathrm{A}}$ for nalbuphine, $0.14 \mathrm{mg} / \mathrm{kg}$ or $370 \mathrm{nmol} / \mathrm{kg}$ per injection, Table 2). Values for $\mathrm{ED}_{50 \text {,control }}$ and $\mathrm{E}_{\mathrm{Am}}$ that were back-calculated from the Black and Leff parameters (see Methods for details) compared well (i.e., $\mathrm{ED}_{50, \text { control }}$ difference $<2$-fold, $\mathrm{E}_{\mathrm{Am}}$ difference $<1.5$-fold) to those actually observed (Tables 1 and 2). Thus, the analytical method was found to be internally consistent.

CCAM effects on nalbuphine-mediated thermal antinociception in rhesus monkeys

Nalbuphine under control conditions failed to produce a full antinociceptive response (i.e., it failed to increase 
tail withdrawal latency to the cutoff latency of $20 \mathrm{~s}$ ) even at the lower-intensity thermal stimulus (i.e., $50^{\circ} \mathrm{C}$; $\mathrm{E}_{\mathrm{Am}}, 19 \mathrm{~s}$; Fig. 3). At $55^{\circ} \mathrm{C}$, it was almost ineffective $\left(\mathrm{E}_{\mathrm{Am}}, 1.3 \mathrm{~s}\right)$. The $\mathrm{ED}_{50, \text { control }}$ was $0.12 \mathrm{mg} / \mathrm{kg}(95 \%$ confidence interval (CI), 0.086-0.18 mg/kg). Administration of $0.1 \mathrm{mg} / \mathrm{kg}$ CCAM SC (12-h pretreatment time) shifted the nalbuphine dose-response curve at $50^{\circ} \mathrm{C} 1.7$-fold to the right $\left(\mathrm{ED}_{50}, 0.20 \mathrm{mg} / \mathrm{kg} ; \mathrm{CI}, 0.15-0.26 \mathrm{mg} / \mathrm{kg}\right)$ and depressed its maximum (asymptotic) values from $19 \mathrm{~s}$ (CI, 17-21 s) to $8.1 \mathrm{~s} \mathrm{(CI,} \mathrm{7.4-8.7} \mathrm{s;} \mathrm{Fig.} \mathrm{3,} \mathrm{top).} \mathrm{At}$ $55^{\circ} \mathrm{C}, 0.1 \mathrm{mg} / \mathrm{kg}$ CCAM shifted the dose-response curve from $0.033 \mathrm{mg} / \mathrm{kg}$ (CI, $0.008-14 \mathrm{mg} / \mathrm{kg}$ ) to $0.071 \mathrm{mg} / \mathrm{kg}$ (CI, $0.00014-35 \mathrm{mg} / \mathrm{kg}$ ) and depressed the maximum tail withdrawal latency from $1.3 \mathrm{~s}$ (CI, 0.91-1.6 s) to $0.66 \mathrm{~s}$ (CI, 0.33-0.99 s; Fig. 3, bottom). Baseline withdrawal latencies (i.e., in absence of nalbuphine) were $0.84 \mathrm{~s}$ (CI, $0-2.3 \mathrm{~s})$ at $50^{\circ} \mathrm{C}$ and $0.44 \mathrm{~s}(\mathrm{CI}, 0-0.97 \mathrm{~s})$ at $55^{\circ} \mathrm{C}$. Note that due to the smaller absolute values and the smaller effect induced by CCAM, the $95 \%$ confidence intervals were much larger for the $55^{\circ} \mathrm{C}$ data than for the $50^{\circ} \mathrm{C}$ data. Nalbuphine efficacy values, tau, were 0.92 at $50^{\circ} \mathrm{C}$ and 0.26 at $55^{\circ} \mathrm{C}$ (Tables 3 and 4 ). The respective apparent in vivo dissociation constants, $\mathrm{K}_{\mathrm{A}}$, were $0.43 \mathrm{mg} / \mathrm{kg}$ or $1100 \mathrm{nmol} / \mathrm{kg}$ at $50^{\circ} \mathrm{C}$ and $0.011 \mathrm{mg} / \mathrm{kg}$ or $29 \mathrm{nmol} / \mathrm{kg}$ at $55^{\circ} \mathrm{C}$. As in the case of the self-administration data, there was a good agreement between back-calculated and observed values for $\mathrm{ED}_{50 \text {,control }}$ and $\mathrm{E}_{\mathrm{Am}}$, indicating internal consistency of the analytical algorithm.

\section{Discussion}

CCAM insurmountably antagonized the effects of alfentanil and nalbuphine both in drug-maintained operant responding and thermal antinociception, rendering the experimental data amenable to a quantitative analysis by the method of partial irreversible antagonism as pioneered by Furchgott (1966) and modified by Black and Leff (1983). Alfentanil displayed a 36-fold higher efficacy in self-administration than in thermoantinociception at $50^{\circ} \mathrm{C}$, suggesting that the mu opioid receptor pool involved in self-administration was indeed 36-fold larger than the receptor pool mediating the mu opioid effect in thermal antinociception (Table 4). In contrast, the apparent in vivo dissociation constant remained essentially the same across the two behavioral paradigms $(<1.3$-fold difference). Nalbuphine's efficacy was 213 -fold higher in self-administration than in thermoantinociception at $50^{\circ} \mathrm{C}$, whereas the apparent in vivo affinity was only $<1.1$-fold higher in self-administration (Table 4). Thus, the observed 60-fold higher potency of alfentanil and 57fold higher potency of nalbuphine in self-administration as compared to thermoantinociception were essentially due to differences in efficacy (and, thus, differences in the size of the respective receptor pool available for agonist interaction). This is not surprising as the neuronal systems mediating the reinforcing properties of drugs (see, e.g., Fibiger and Phillips 1988; Goldstein 1989; DiChiara and North 1992; Koob 1992) are thought to be strikingly different from those mediating thermoantinociception (see, e.g., Nieuwenhuys et al. 1978; Duggan and North 1984; Holzer 1991). The fact that the apparent in vivo affinities were essentially the same for both behavioral paradigms suggests that both behaviors are mediated by the same mu opioid receptor subtype (or that both agonists tested do not differentiate between mu receptor subtypes in these behavioral tests). This finding corroborates previous experiments using opioid antagonists (for a review see Woods et al. 1992).

The quantitative analysis also revealed that alfentanil was of 2-fold higher efficacy than nalbuphine in self-administration and of 12-fold higher efficacy than nalbuphine in thermoantinociception at $50^{\circ} \mathrm{C}$ (Table 4). The efficacy differences could also be seen on a purely qualitative level in both behavioral paradigms: in self-administration, nalbuphine-maintained responding was more strongly inhibited than alfentanil-maintained responding at both CCAM doses tested. In our thermoantinociception assays, only alfentanil was fully effective at the highest intensity stimulus tested (i.e., $55^{\circ} \mathrm{C}$; Zernig et al. 1994), whereas nalbuphine was almost ineffective (Walker et al. 1995; present study). Even at the lower stimulus intensity (i.e., $50^{\circ} \mathrm{C}$ ), nalbuphine was not fully effective (Fig. 3). As in self-administration, CCAM affected nalbuphine's thermoantinociceptive effects more strongly than those of alfentanil. The same criterion had previously been used by Adams et al. (1990) to establish efficacy rank orders for mu opioid agonists in thermoantinociception; the identity of the qualitative and quantitative rank orders in the present study (obtained in two different behavioral assays) provides further validation of the qualitative approach. Finally, partial inactivation of mu opioid receptors by CCAM flattened dose-response curves for nalbuphine at lower stimulus intensities than for alfentanil (Zernig et al. 1994; present study). In all these aspects, nalbuphine acted very similar to another low-efficacy mu opioid agonist, morphine (Adams et al. 1990; Zernig et al. 1994; Walker et al. 1995).

There were, however, unexpected findings when comparing 50 and $55^{\circ} \mathrm{C}$ thermoantinociception experiments themselves. In contrast to a previous analysis (which had used an inferior fitting algorithm; Zernig et al. 1994), the present analysis showed that alfentanil efficacies were essentially identical at 50 and $55^{\circ} \mathrm{C}$ (Tables 3 and 4 ). This is counterintuitive, as it would be expected that an increase in the thermal stimulus intensity (i.e., from 50 to $55^{\circ} \mathrm{C}$ ) would produce a larger nociceptive response, the effective neutralization of which would require a larger fraction of $\mathrm{mu}$ opioid receptors to be occupied by the agonist. Indeed, this expectation was fulfilled by nalbuphine which showed a decrease in efficacy for the higher-intensity thermonociceptive stimulus. Furthermore, both alfentanil and nalbuphine showed changes in apparent in vivo affinity across test temperatures (alfentanil, 7.5-fold affinity decrease with increasing temperature; nalbuphine, 14fold increase). For nalbuphine at $55^{\circ} \mathrm{C}$, these unexpected findings could be explained by the fact that the overall antinociceptive response mediated by nalbuphine was ex- 
tremely small and thus conducive to an erroneous analysis. The unexpected results for alfentanil can be less easily explained, as it yielded a robust raw signal (Zernig et al. 1994). Additionally, the $95 \%$ confidence intervals for the $\mathrm{K}_{\mathrm{A}}$ values were nonoverlapping. However, analysis of model data had shown that the algorithm used in the present study yields confidence intervals for $\mathrm{K}_{\mathrm{A}}$ and other parameters that - although being numerically correct might be too small (Zernig et al. 1996b). Accordingly, we had advised the readers to regard any affinity and efficacy differences that are smaller than 10-fold with extreme caution (Zernig et al. 1996b). Further analysis of a larger number of opioid agonists will show if the counterintuitive numerical results mentioned above are a general phenomenon. The fact that the affinity changes across temperatures were of opposite directions for alfentanil and nalbuphine indicates that the numerical differences might indeed be coincidental.

The dimension of $\mathrm{K}_{\mathrm{A}}$ was not expressed identically for the two behavioral paradigms, i.e., it was " $\mathrm{mg} / \mathrm{kg}$ " in a cumulative dosing procedure in thermoantinociception whereas it was " $\mathrm{mg} / \mathrm{kg}$ per injection" in the self-administration paradigm. The cumulative dosing procedure employed in the thermoantinociception assays, however, consistently used 3.2-fold (i.e., half-logarithmic) increases in dose to construct dose-response curves. Therefore, the actual single dose given was always a constant fraction, i.e., $68 \%$, of the nominal cumulative dose. Thus, for a comparison, both affinity values might be reduced to the dimension: "mg/kg per injection" without too much loss of quantitative precision for the thermoantinociception assay. The other major difference in drug administration between the two paradigms was the route of administration, i.e., intravenous in self-administration versus subcutaneous in thermoantinociception. Apparently, this difference did not result in large difference in estimated apparent in vivo affinities (Table 4), suggesting that the distribution of these mu opioid agonists is similar for both routes of administration.

With regard to the possible clinical usefulness of CCAM, it should be noted that CCAM insurmountably antagonized the effects of both tested mu opioid agonists in a behavioral paradigm with high face validity for human drug abuse (Bozarth 1987; Stolerman 1992). CCAM's insurmountable antagonism (i.e., the flattening of the dose-response curves) occurred in a behavioral paradigm in which the competitive mu opioid antagonist quadazocine produces simple parallel shifts of both alfentanil and nalbuphine dose-response curves over the same dose range (Bertalmio and Woods 1989; Winger et al. 1992; Winger et al. 1996): even when given at doses that were 100 - to 1000 -fold higher than the maximally reinforcing doses under control conditions, the two tested opioid agonists were almost devoid of any reinforcing effects in CCAM-pretreated animals. In addition, sensitivity to the reinforcing effects of alfentanil and nalbuphine recovered to pre-CCAM levels very slowly, i.e., within 4-7 days. Both the insurmountable antagonism and the long-lasting effect render CCAM a promising compound in the prevention of opioid abuse. Surprisingly, the time course of receptor recovery was not significantly delayed if a single dose of $1 \mathrm{mg} / \mathrm{kg}$ CCAM was followed by daily injections of $0.1 \mathrm{mg} / \mathrm{kg}$ CCAM, although a single dose of $0.1 \mathrm{mg} / \mathrm{kg}$ CCAM acutely depressed the receptor population to $3-10 \%$ of the preCCAM level. Maybe the repeated administration of CCAM resulted in increasing its metabolism; further work is necessary to answer that question. In mice, it has been shown that daily administration of $1 \mathrm{mg} / \mathrm{kg}$ CCAM is sufficient to keep the mu receptor population at a constant low level (G. Zernig, unpublished observation). Due to the scarcity of the compound, however, this has not been tried yet in rhesus monkeys.

Acknowledgements This work was supported by the Austrian Science Foundation Grants J0697-MED and J0882-MED, by a NIDA INVEST Fellowship (to G. Z.) and USPHS Grants DA 00254 and DA 04403. The Research Technology Branch of National Institute on Drug Abuse is thanked for providing most of the drugs used in the present study. G. Z. wants to express special thanks to Dr. Gail Winger, Debbie Huntzinger and Brenda Winger for taking him under their wings.

\section{References}

Adams RU, Paronis CA, Holtzman SG (1990) Assessment of relative intrinsic activity of mu-opioid analgesics in vivo by using beta-funaltrexamine. J Pharmacol Exp Ther 255: 1027-1032

Bertalmio AJ, Woods JH (1989) Reinforcing effect of alfentanil is mediated by mu opioid receptors: apparent $\mathrm{pA}_{2}$ analysis. J Pharmacol Exp Ther 251: 455-460

Black JW, Leff P (1983) Operational models of pharmacological agonism. Proc R Soc Lond B 220: 141-162

Black JW, Leff P, Shankley NP, Wood J (1985) An operational model of pharmacological antagonism: The effect of E/[A] curve shape on agonist dissociation constant estimation. Br J Pharmacol 84: 561-571

Bozarth MA (1987) Methods of assessing the reinforcing properties of abused drugs. Springer, New York

Burke TF, Woods JH, Lewis JW, Medzihradsky F (1994) Irreversible opioid antagonist effects of clocinnamox on opioid analgesia and mu receptor binding in mice. J Pharmacol Exp Ther 271: 715-721

Comer SD, Burke TF, Lewis JW, Woods JH (1992) Clocinnamox: a novel, systemically-active irreversible opioid antagonist. J Pharmacol Exp Ther 262: 1051-1056

Deneau G, Yanagita T, Seevers MH (1969) Self-administration of psychoactive substances by the monkey. A measure of psychological dependence. Psychopharmacologia 16: 30-48

DiChiara G, North RA (1992) Neurobiology of opiate abuse. Trends Pharmacol Sci 13: 185-193

Duggan AW, North RA (1984) Electrophysiology of opioids. Pharmacol Rev 35: 219-281

Dykstra LA, Woods JH (1986) A tail withdrawal procedure for assessing analgesic activity in rhesus monkeys. J Pharmacol Meth 15: 263-269

Fibiger HC, Phillips AG (1988) Mesocorticolimbic dopamine systems and reward. Ann NY Acad Sci 57: 206-215

Furchgott RF (1966) The use of $\beta$-haloalkylamines in the differentiation of receptors and in the determination of dissociation constants of receptor-agonist complexes. Adv Drug Res 3: $21-56$

Goldstein A (1989) Molecular and cellular aspects of the drug addiction. Springer, New York

Holzer P (1991) Capsaicin: cellular targets, mechanisms of action, and selectivity for thin sensory neurons. Pharmacol Rev 43: 143-201 
Koob GF (1992) Drugs of abuse: anatomy, pharmacology and function of reward pathways. Trends Pharmacol Sci 13: 177-184

Nieuwenhuys R, Voogd J, vanHuijzen C (1978) The human central nervous system. Springer, New York

Portoghese PS, Larson DL, Sayre LM, Fries DS, Takemori AE (1980) A novel opioid receptor site directed alkylating agent with irreversible narcotic antagonistic and reversible agonistic activities. J Med Chem 23: 233-234

Stolerman I (1992) Drugs of abuse: behavioural principles, methods and terms. Trends Pharmacol Sci 13: 170-176

Takemori AE, Larson DL, Portoghese PS (1981) The irreversible narcotic antagonistic and reversible agonistic properties of the fumarate methyl ester derivative of naltrexone. Eur J Pharmacol 70: 445-451

Walker EA, Zernig G, Woods JH (1995) Buprenorphine antagonism of mu opioids in the rhesus monkey tail-withdrawal procedure. J Pharmacol Exp Ther 273: 1345-1352

Winger G, Palmer RK, Woods JH (1989) Drug-reinforced responding: rapid determination of dose-response functions. Drug Alcohol Depend 24: 135-142

Winger G, Skjoldager P, Woods JH (1992) Effects of buprenorphine and other opioid agonists and antagonists on alfentaniland cocaine-reinforced responding in rhesus monkeys. J Pharmacol Exp Ther 261: 311-317

Winger G, Woods JH, Hursh SR (1996) Behavior maintained by alfentanil or nalbuphine in rhesus monkeys: fixed-ratio and time-out changes to establish demand curves and relative reinforcing effectiveness. Exp Clin Psychopharmacol 4: 131-141
Woods JH, Winger G, France CP (1992) Use of in vivo apparent $\mathrm{pA}_{2}$ analysis in assessment of opioid abuse liability. Trends Pharmacol Sci 13: 282-286

Young AM, Swain HH, Woods JH (1981) Comparison of opiod agonists in maintaining responding and in suppressing morphine withdrawal in rhesus monkeys. Psychopharmacology 74: $329-335$

Zernig G, Butelman ER, Lewis JW, Walker EA, Woods JH (1994) In vivo determination of mu opiod receptor turnover in rhesus monkeys after irreversible blockade with clocinnamox. J Pharmacol Exp Ther 269: 57-65

Zernig G, Broadbear JH, Lewis JW, Brine GA, Woods JH (1995a) Opioid agonist effects on mouse writhing after irreversible mu receptor blockade with clocinnamox. Exp Clin Psychopharmacol 3: 323-329

Zernig G, Issaevitch T, Broadbear J, Burke T, Lewis JW, Brine GA, Woods JH (1995b) Receptor reserve and affinity of mu opioid agonists in mouse antinociception: correlation with receptor binding. Life Sci 57: 2113-2125

Zernig G, Burke T, Lewis JW, Woods JH (1996a) Mechanism of clocinnamox blockade of opioid receptors: evidence from in vitro and ex vivo binding and behavioral assays. J Pharmacol Exp Ther 279: 23-31

Zernig G, Issaevitch T, Woods JH (1996b) Calculation of agonist efficacy, apparent affinity and receptor population changes after administration of insurmountable antagonists: comparison of different analytical approaches. J Pharmacol Toxicol Meth 35: $223-237$ 